\title{
Elective surgery resource utilization
}

\author{
David A. Magno-Padron ${ }^{1} \cdot$ Kathleen A. Holoyda ${ }^{1} \cdot$ Whitney Moss · Giovanna Pires ${ }^{1} \cdot$ Gentry C. Carter ${ }^{2}$. \\ Jayant P. Agarwal ${ }^{1}$. Alvin C. Kwok ${ }^{3}$
}

Received: 10 August 2021 / Accepted: 18 October 2021 / Published online: 25 October 2021

(c) The Author(s), under exclusive licence to Springer-Verlag GmbH Germany, part of Springer Nature 2021

\begin{abstract}
Purpose Cessation of elective surgery during COVID-19 was partly driven by concern for consumption of hospital resources required by critically ill patients. We aim to determine the extent of resource utilization by elective outpatient surgery to assist in ensuring future resource conservation decisions are data driven.

Methods The study utilized a retrospective cohort gathered from the American College of Surgeons National Surgical Quality Improvement Program database. Participants were adult patients who underwent elective or non-elective surgery between 2017 and 2018. Outcomes included patient characteristics and post-operative outcomes for elective and non-elective surgeries. Post-operative outcomes were used as a surrogate for the consumption of hospital resources.

Results A total of 1,558,938 (79.8\%) elective and 393,339 (20.2\%) non-elective surgeries were identified. Elective surgery patients were more likely to be outpatient status, have an ASA class $<3$, and exhibited lower rates of prolonged ventilation, 30-day reoperation, and 30-day readmissions, and averaged 5 days less of inpatient stay. Elective outpatient surgery (vs. elective inpatient surgery) averaged shorter operative times and exhibited lower rates of readmissions $(2.1 \%$ vs. $5.5 \% ; p<0.001)$, reoperations $(1.1 \%$ vs. $2.8 \% ; p<0.001)$, prolonged ventilation $(0.0 \%$ vs. $0.3 \% ; p<0.001)$, and 30 -day mortality $(0.1 \%$ vs. $0.5 \% ; p<0.001)$ and accounted for $30.2 \%$ of the overall relative value units $(\$ 339,815,038)$.

Conclusion We evaluated utilization of hospital resources by patients undergoing elective outpatient surgery by identifying surgeries performed in 2017-2018 then stratifying them by outpatient status. Elective outpatient surgeries consumed negligible amounts of hospital resources and should not be considered a threat to resources in the setting of high demand by critically ill COVID-19 patients.
\end{abstract}

Keywords COVID $\cdot$ Coronavirus $\cdot$ Elective surgery $\cdot$ Ventilator use $\cdot$ Resource utilization

\section{Introduction}

In an effort to conserve healthcare resources, the American College of Surgeons (ACS) published guidelines on March 13, 2020, which recommended to hospitals, health systems, and surgeons to "thoughtfully review all scheduled elective surgical procedures with a plan to minimize, postpone, or

Alvin C. Kwok

Alvin.kwok@hsc.utah.edu

1 Division of Plastic Surgery, University of Utah School of Medicine, Salt Lake City, UT, USA

2 Department of Population Health Sciences, University of Utah School of Medicine, Salt Lake City, UT, USA

3 Department of Surgery, Division of Plastic Surgery, University of Utah School of Medicine, 30 North 1900 East, 3B400, Salt Lake City, UT 84132, USA cancel electively scheduled operations" [1]. While difficult to estimate, cancellation of elective surgery, however briefly, has undoubtedly impacted patient morbidity, mortality, disease progression, and the financial status of physicians and hospital systems alike.

As restrictions on elective surgeries have ceased, it is essential to determine how utilization of hospital resources in future national emergencies, like COVID-19, can be data driven, cost-effective, and ultimately best for patients and the healthcare system. To assist in this endeavor, we queried the American College of Surgeons National Surgical Quality Improvement Program (ACS-NSQIP) database to provide a description of patient characteristics and general post-operative outcomes for all elective and non-elective procedures performed in recent years to better understand surgical resource utilization, specifically. 


\section{Material and methods}

The ACS-NSQIP database is a validated national outcomes database that aims to improve the surgical quality and care of patients. An in-depth explanation of the database's methods for data collection has previously been published [2].

All elective inpatient and outpatient cases performed from 2017 to 2018 were identified using the NSQIP database. Procedures with operative times above and below two standard deviations of the mean were excluded to control for outliers. Patient demographic and comorbidity information included age, ethnicity (white, black, unknown), and American Society of Anesthesiologist classification score (ASA class). Perioperative variables included admission status, operative time, 30-day rates of mortality, readmission, reoperation, prolonged intubation (ventilator requirement $>48 \mathrm{~h}$ ), and length of stay; these variables were selected to represent high-demand resources during the COVID-19 pandemic.

A brief evaluation of overall costs was performed by extracting work relative value units (RVUs) from the database using the variable "WORKRVU." The Medicare Conversion Factors for 2017 and 2018 were US \$35.887/RVU and US $\$ 35.999 / \mathrm{RVU}$, [3] respectively, which average to US $\$ 35.94$ over the 2-year study period.

Continuous variables were presented as mean-averages with standard deviations. Categorical variables were presented as total counts and percentages.

Our study protocol was reviewed by the University of Utah Institutional Review Board and was given an exempt status.

\section{Results}

The NSQIP database was queried for all elective and nonelective surgeries that occurred between 2017 and 2018 . This resulted in 1,558,938 (79.8\%) elective and 393,339 (20.2\%) non-elective surgeries included in the analysis.

Patient characteristics and outcomes are presented for each cohort (Table 1); all variables and outcomes were significantly different between the cohorts. Compared to nonelective surgery, elective surgery patients were more likely to be outpatient status $(52.2 \%$ vs. $18.1 \%)$ and healthier as determined by the proportion of patients with an ASA class of $<3(56.5 \%$ vs. $43.1 \%)$. The rates of post-operative resource utilization were all lower in elective surgery such as prolonged ventilation ( $0.2 \%$ vs. $2.7 \%)$, 30-day reoperation $(1.9 \%$ vs. $4.4 \%)$, and 30 -day readmissions $(3.7 \%$ vs. $7.7 \%)$. Elective surgeries also averaged nearly 5 days less
Table 1 Elective vs. non-elective surgery patients

\begin{tabular}{|c|c|c|c|}
\hline & Non-elective & Elective & $p$-value \\
\hline$n$ & $20.2(393,399)$ & $79.8(1,558,938)$ & \\
\hline Age & $56.82(20.34)$ & $56.55(16.12)$ & $<0.001$ \\
\hline Sex & $<0.001$ & & \\
\hline - Female & $53.6(211,041)$ & $58.4(909,926)$ & $<0.001$ \\
\hline - Male & $46.4(182,356)$ & $41.6(649,011)$ & \\
\hline Race & $<0.001$ & & \\
\hline - White & $65.7(258,492)$ & $70.4(1,097,751)$ & \\
\hline - Black & $10.7(41,922)$ & $9.9(154,644)$ & \\
\hline - Unknown & $19.5(76,841)$ & $16.0(249,557)$ & \\
\hline ASA class & $<0.001$ & & \\
\hline$-\mathrm{I}$ & $9.6(37,574)$ & $8.2(127,977)$ & \\
\hline - II & $33.5(131,269)$ & $48.3(750,580)$ & \\
\hline - III & $41.5(162,957)$ & $40.2(625,529)$ & \\
\hline - IV & $14.6(57,384)$ & $3.3(51,161)$ & \\
\hline$-\mathrm{V}$ & $0.8(3169)$ & $0.0(131)$ & \\
\hline Admission status & $<0.001$ & & \\
\hline - Inpatient & $81.9(322,073)$ & $47.8(744,634)$ & \\
\hline - Outpatient & $18.1(71,326)$ & $52.2(814,304)$ & \\
\hline Operative time & $80.65(53.20)$ & $100.58(63.54)$ & $<0.001$ \\
\hline Mortality & $3.8(14,944)$ & $0.3(4285)$ & $<0.001$ \\
\hline Readmission & $<0.001$ & & \\
\hline - No & $0.2(953)$ & $0.2(2986)$ & \\
\hline - Null & $92.1(362,333)$ & $96.1(1,498,303)$ & \\
\hline - Yes & $7.7(30,113)$ & $3.7(57,649)$ & \\
\hline Reoperation & $<0.001$ & & \\
\hline - No & $95.6(376,053)$ & $98.1(1,529,143)$ & \\
\hline - Yes & $4.4(17,346)$ & $1.9(29,795)$ & \\
\hline Vent $>48 \mathrm{~h}$ & $2.7(10,638)$ & $0.2(2714)$ & $<0.001$ \\
\hline Length of stay & $6.28(7.71)$ & $1.66(3.16)$ & $<0.001$ \\
\hline Surgical specialty & $<0.001$ & & \\
\hline - Cardiac & $2,023(0.5 \%)$ & $3,595(0.2 \%)$ & \\
\hline - General & $240,165(61 \%)$ & $592,832(38 \%)$ & \\
\hline - Gynecology & $10,791(2.7 \%)$ & $175,568(11 \%)$ & \\
\hline $\begin{array}{l}\text { - Interventional radiol- } \\
\text { ogy }\end{array}$ & $95(<0.1 \%)$ & $213(<0.1 \%)$ & \\
\hline - Neurosurgery & $16,324(4.1 \%)$ & $81,575(5.2 \%)$ & \\
\hline - Orthopedics & $80,529(20 \%)$ & $408,058(26 \%)$ & \\
\hline - Otolaryngology & $1,886(0.5 \%)$ & $48,393(3.1 \%)$ & \\
\hline - Plastics & $3,206(0.8 \%)$ & $53,053(3.4 \%)$ & \\
\hline - Thoracic & $3,414(0.9 \%)$ & $18,958(1.2 \%)$ & \\
\hline - Urology & $6,619(1.7 \%)$ & $106,503(6.8 \%)$ & \\
\hline - Vascular & $28,347(7.2 \%)$ & $70,189(4.5 \%)$ & \\
\hline
\end{tabular}

of inpatient stay (6.28 days vs. 1.66 days). By specialty, general surgery and orthopedics made up the majority of both elective and non-elective cases (general surgery: $61 \%$ of non-elective, $38 \%$ of elective; orthopedics: $20 \%$ of nonelective, $26 \%$ of elective). 
Table 2 Elective inpatient vs. outpatient surgery patients

\begin{tabular}{|c|c|c|c|}
\hline & Inpatient & Outpatient & $p$-value \\
\hline$N$ & $47.8(744,634)$ & $52.2(814,304)$ & \\
\hline Age & $60.64(14.64)$ & $52.80(16.50)$ & $<0.001$ \\
\hline Sex & $<0.001$ & & \\
\hline - Female & $57.5(428,145)$ & $59.2(481,781)$ & $<0.001$ \\
\hline - Male & $42.5(316,489)$ & $40.8(332,522)$ & \\
\hline Race & $<0.001$ & & \\
\hline - White & $68.2(507,838)$ & $72.4(589,913)$ & \\
\hline - Black & $9.7(72,518)$ & $10.1(82,126)$ & \\
\hline - Unknown & $18.6(138,686)$ & $13.6(110,871)$ & \\
\hline ASA class & $<0.001$ & & \\
\hline - I & $3.4(25,319)$ & $12.6(102,658)$ & \\
\hline - II & $41.4(307,377)$ & $54.6(443,203)$ & \\
\hline - III & $50.4(374,548)$ & $30.9(250,981)$ & \\
\hline - IV & $4.8(35,961)$ & $1.9(15,200)$ & \\
\hline$-\mathrm{V}$ & $0.0(3577)$ & $0.0(41)$ & \\
\hline Operative time & $126.28(64.63)$ & 77.07 (52.47) & $<0.001$ \\
\hline Mortality & $0.5(3577)$ & $0.1(708)$ & $<0.001$ \\
\hline Readmission & $<0.001$ & & \\
\hline - No & $0.2(1491)$ & $0.2(1495)$ & \\
\hline - Null & $94.3(702,471)$ & $97.7(795,832)$ & \\
\hline - Yes & $5.5(40,672)$ & $2.1(16,977)$ & \\
\hline Reoperation & $<0.001$ & & \\
\hline - No & $97.2(723,962)$ & $98.9(805,181)$ & \\
\hline - Yes & $2.8(20,672)$ & $1.1(9123)$ & \\
\hline Vent $>48 \mathrm{~h}$ & $0.3(2534)$ & $0.0(171)$ & $<0.001$ \\
\hline Length of stay & $3.07(3.72)$ & N/A & $<0.001$ \\
\hline Surgical specialty & $<0.001$ & & \\
\hline - Cardiac & $3,477(0.5 \%)$ & $118(<0.1 \%)$ & \\
\hline - General & $242,135(33 \%)$ & $350,697(43 \%)$ & \\
\hline - Gynecology & $61,053(8.2 \%)$ & $114,515(14 \%)$ & \\
\hline - Interventional radiology & $70(<0.1 \%)$ & $143(<0.1 \%)$ & \\
\hline - Neurosurgery & $52,515(7.1 \%)$ & $29,060(3.6 \%)$ & \\
\hline - Orthopedics & $249,684(34 \%)$ & $158,374(19 \%)$ & \\
\hline - Otolaryngology & $10,738(1.4 \%)$ & $37,655(4.6 \%)$ & \\
\hline - Plastics & $8,315(1.1 \%)$ & $44,738(5.5 \%)$ & \\
\hline - Thoracic & $17,846(2.4 \%)$ & $1,112(0.1 \%)$ & \\
\hline - Urology & $51,375(6.9 \%)$ & $55,128(6.8 \%)$ & \\
\hline - Vascular & $47,425(6.4 \%)$ & $22,764(2.8 \%)$ & \\
\hline
\end{tabular}

Our subgroup analysis stratified the elective surgery cohort by admission status, inpatient vs. outpatient (Table 2); all variables and outcomes were significantly different between the cohorts. Half (52.2\%) of elective surgeries were performed on an outpatient basis and represented a younger (52.8 years vs. 60.6 years) and healthier patient population (ASA class $<3,67.2 \%$ vs. $44.8 \%$ ). Resource utilization was substantially lower for the outpatient cohort in several categories including 30-day readmissions ( $2.1 \%$ vs. $5.5 \%), 30$-day reoperations ( $1.1 \%$ vs. $2.8 \%$ ), and operative
Table 3 RVU for all cohorts

\begin{tabular}{lrl}
\hline & Total RVU & Compensation \\
\hline Non-elective & $5,859,100$ & $\$ 210,576,054$ \\
Elective* & $25,312,609$ & $\$ 909,735,167$ \\
- Inpatient** & $15,860,174$ & $\$ 570,014,653$ \\
- Outpatient & $9,452,435$ & $\$ 339,720,514$ \\
\hline${ }^{*} p$-value: $<0.001$ (elective vs. non-elective) & \\
${ }^{* *} p$-value: $<0.001$ (elective inpatient vs. elective outpatient)
\end{tabular}

time (77.1 $\mathrm{min}$ vs. $126.3 \mathrm{~min}$ ); a smaller difference was appreciated in prolonged ventilation $(0.0 \%$ vs. $0.3 \%)$ and 30 -day mortality $(0.1 \%$ vs. $0.5 \%)$. General surgery made up the highest volume of elective outpatient cases (43\%), while orthopedics had the highest volume of elective inpatient cases (34\%).

Total RVUs and their conversion to physician compensation are presented for each cohort (Table 3). Total RVU accumulated for all surgeries was $31,171,709(\$ 1,120,622,939)$, with elective surgery accounting for $81.2 \%(\$ 909,988,293)$ of the overall RVUs produced during the study period. Elective outpatient surgeries represented 9,452,435 RVUs $(\$ 339,815,038)$ or $30.2 \%$ of the overall RVUs.

\section{Discussion}

We provide a snapshot of the patient demographics, comorbidities, and perioperative outcomes associated with elective surgery in the recent years prior to the COVID-19 pandemic. Resource utilization was considerably lower in elective surgery than in non-elective surgery and is represented by rates of reoperation and prolonged ventilation, and length of hospital stay. Our subgroup analysis revealed that elective outpatient surgery utilized significantly less resources than inpatient surgery which was best represented by decreased operative time in the outpatient cohort. Lastly, the elective outpatient surgery cohort represented roughly one-third of the overall RVUs during the study period.

Though the overall strain on hospital systems by the COVID-19 pandemic will not be able to be truly quantified, the cessation of elective outpatient surgery gave an opportunity to re-evaluate hospital resource utilization in the USA. Because of this pause, many patients had delayed medical care and the consequences from this will be difficult to quantify [4]. In April of 2020, the ACS published guidelines to inform surgeons, hospitals, and health systems on how to resume elective surgery [5]. Our national analysis supports this resumption as evidenced by the negligible utilization of hospital resources by elective outpatient surgeries and implies that in the future, ceasing elective surgery may not be necessary. We also provide general insight on the revenue 
that the healthcare system stands to lose and gradually regain when elective outpatient surgical cases are stopped.

Specifically, with COVID-19, a recent prospective cohort study revealed that patients ageg $\geq 65$ or those with heart failure and chronic kidney disease represented the greatest risk factors for hospital admission [6]. Our elective outpatient surgery cohort had an average age of 52 years and twothirds were either ASA class I or II. These patients may therefore be at less risk for developing significant complications if infected with COVID-19.

The ACS's statement on restarting elective surgeries requires hospitals to have available resources such as beds and ventilators, both of which we show will be minimally impacted by elective outpatient surgery [5, 7]. Additionally, anesthesia-sedation medications have been listed as required resources. [7] We revealed that elective outpatient surgery averaged $50 \mathrm{~min}$ less of operative time than the inpatient cohort, which will translate to substantially less consumption of these medications.

The department of surgery and its specialties generate $40-70 \%$ of a hospital's revenue [8]. In general, surgical patients with short lengths of stay will generate the greatest income for hospitals [9]. We found that elective outpatient surgery accounts for an estimated one-third of overall surgical revenue.

Limitations of the ACS-NSQIP database have been well described [10], [11]. The NSQIP database provides information from only a sample of unidentified participating hospitals in the USA, and thus, some of our results may be less applicable to areas of the country, such as rural settings. Additionally, this data may be less generalizable to other countries with different types of healthcare delivery systems. Furthermore, the post-operative outcomes we present are only one aspect of the decision-making process required by hospitals and policymakers when discussing resource utilization and elective surgery. Other aspects may include the acuity of the patient's presentation and their risk for disease progression. Similarly, the work RVUs and associated costs are only a few variables that contribute to hospital margins,further costs analyses cannot be performed using only the NSQIP database.

\section{Conclusion}

This study presents insight and descriptive evidence into how elective surgery cases utilize hospital resources and affect hospital funding using recent national outcomes. We believe that elective outpatient surgery can be performed with minimal impact on a hospital's resources that had previously been reserved for COVID-19 patients. This information will remain valuable for future analyses on the true impact imparted on the healthcare system by COVID-19 and will help guide resource utilization conversations in the future.

Authors' contributions All authors above appropriately contributed to the development of this manuscript. The conceptualization of the goals/ aims of the article were driven by Kathleen Holoyda, Jayant Agarwal, and Alvin Kwok. The formal acquisition and analysis of the data were carried out by Gentry Carter. David Magno-Padron, Whitney Moss, and Giovanna Pires were involved in interpreting the data, drafting, revising, and approving the final version for submission.

Availability of data and material Available.

Code availability Available.

\section{Declarations}

Ethics approval This article does not contain any studies with human participants or animals performed by any of the authors.

Conflict of interest David A. Magno-Padron declares that he has no conflict of interest. Kathleen A. Holoyda declares that she has no conflict of interest. Whitney Moss declares that she has no conflict of interest. Giovanna Pires declares that she has no conflict of interest. Gentry C. Carter declares that she has no conflict of interest. Jayant P. Agarwal declares that he receives funds through consulting work with Don Joy Orthopedics; however, this is unrelated to the current project. Alvin C. Kwok declares that he has no conflict of interest.

\section{References}

1. American College of Surgeons. COVID-19: Recommendations for Management of Elective Surgical Procedures. Available at: https://www.facs.org/covid-19/clinical-guidance/elective-surgery. Accessed June 01, 2020

2. American College of Surgeons. User Guide for the 2016 ACS NSQIP Participant Use File. Available at: https://www.facs.org/-/ media/files/quality-programs/nsqip/nsqip_puf_userguide_2016. ashx.

3. Centers for Medicare and Medicaid Services. Proposed Policy, Payment, and Quality Provisions Changes to the Medicare Physician Fee Schedule for Calendar Year 2018. Available at: https:// www.cms.gov/newsroom/fact-sheets/proposed-policy-paymentand-quality-provisions-changes-medicare-physician-fee-sched ule-calendar-year. Accessed June 01, 2020

4. Weinstein E, Ragazzoni L, Burkle F, et al. Delayed Primary and Specialty Care: The Coronavirus Disease-2019 Pandemic Second Wave. Disaster Med Public Health Prep. 2020:1-3.

5. American College of Surgeons. Joint Statement: Roadmap for Resuming Elective Surgery after COVID-19 Pandemic. Available at: https://www.facs.org/covid-19/clinical-guidance/roadmap-elect ive-surgery. Accessed June 01, 2020.

6. Petrilli CM, Jones SA, Yang J, et al. Factors associated with hospital admission and critical illness among 5279 people with coronavirus disease 2019 in New York City: prospective cohort study. BMJ. 2020;369:m1966.

7. American College of Surgeons. Local Resumption of Elective Surgery Guidance. Available at: https://www.facs.org/covid-19/clini cal-guidance/resuming-elective-surgery. Accessed June 01, 2020. 
8. Doebbeling BN, Burton MM, Wiebke EA et al (2012) Optimizing perioperative decision making: improved information for clinical workflow planning. AMIA Annu Symp Proc 2012:154-163

9. Boggs SD, Tan DW, Watkins CL, Tsai MH (2019) OR Management and Metrics: How It All Fits Together for the Healthcare System. J Med Syst 43(6):147

10. Epelboym I, Gawlas I, Lee JA et al (2014) Limitations of ACSNSQIP in reporting complications for patients undergoing pancreatectomy: underscoring the need for a pancreas-specific module. World J Surg 38(6):1461-1467
11. Sippel RS, Chen H (2011) Limitations of the ACS NSQIP in thyroid surgery. Ann Surg Oncol 18(13):3529-3530

Publisher's Note Springer Nature remains neutral with regard to jurisdictional claims in published maps and institutional affiliations. 